\title{
Evaluation of severe acute maternal morbidity and mortality at a tertiary referral center of Uttarakhand, India
}

\author{
Lipi Verma*, Ruchira Nautiyal, Pradeep Aggarwal
}

Department of Obstetrics and Gynecology, SRHU Jolly Grant, Dehradun, Uttarakhand, India

Received: 04 February 2019

Accepted: 06 March 2019

*Correspondence:

Dr. Lipi Verma,

E-mail: vermalipi@yahoo.com

Copyright: (C) the author(s), publisher and licensee Medip Academy. This is an open-access article distributed under the terms of the Creative Commons Attribution Non-Commercial License, which permits unrestricted non-commercial use, distribution, and reproduction in any medium, provided the original work is properly cited.

\begin{abstract}
Background: Maternal mortality is an area of concern for the Governments across the globe. India is signatory to millennium declaration and is committed to achieving the target of millennium development goals by reducing MMR to 100 . Known obstacles to reducing the MMR in developing countries, include lack of material and human resources, as well as difficulties in accessing services due to financial, geographical, and cultural limitations.

Methods: It was a descriptive cross-sectional study conducted at a tertiary care centre in Uttarakhand for a period of one year. WHO's near-miss approach was implemented for evaluation of severe maternal outcomes and to assess the quality of maternal health care.

Results: During the period of this study there were 2243 total antenatal admissions, 1675 deliveries, 1591 live births and 59 near miss cases. Prevalence of SAMM in the present study is 3.52\%. Out of every 9-10 women who survived a life-threatening condition 1 died. Mortality Index is $10.17 \%$. Maternal mortality ratio is 377.12 per 1 lakh live births. A total of 43 patients with potentially life-threatening conditions were admitted in ICU out of which 26 were near miss cases. The leading cause of near miss in this tertiary health facility is obstetric haemorrhage (45.8\%).

Conclusions: Prompt identification of complications and timed intervention remains the key determinant in making mothers survive a life-threatening complication.
\end{abstract}

Keywords: Live births, Maternal mortality, SAMM

\section{INTRODUCTION}

Maternal mortality is an area of concern for the Governments across the globe. The Millennium Development Goal 5 (MDG 5) target of reducing the (MMR) maternal mortality ratio (target 5A) by three fourths between 1990 and 2015 remains a challenge.

Less than $40 \%$ of countries have a complete civil registration system with good attribution of cause of death, which is necessary for the accurate measurement of maternal mortality. ${ }^{1,2}$ In 1990, the estimated MMR was 437 per 10,000 live births. ${ }^{1}$ The maternal mortality ratio (MMR) of India was 254 from 2004 to 2006, which was reduced to 200 in the year 2010 . Known obstacles to reducing the MMR in developing countries, include lack of material and human resources, as well as difficulties in accessing services due to financial, geographical, and cultural limitations. ${ }^{3}$

Recently Sustainable development goal 3: to ensure healthy lives and promote well-being for all at all ages recommends to reduce global maternal mortality ratio to less than 70 per 100,000 live births by the year $2030 .{ }^{4}$

\section{METHODS}

A descriptive, cross sectional study was carried out for a period of 1year from May 2016 to April 2017 at Obstetrics and Gynecology Department of Himalayan 
institute of medical sciences SRHU Dehradun. Potentially life-threatening conditions were diagnosed, and those cases which met WHO 2009 criteria for near miss were selected.

Maternal mortality during the same period was also analyzed. Near miss cases from patients presenting in Emergency and IPD of hospital with severe complications of pregnancy during the study period were recruited.

\section{Inclusion criteria}

- Women who were pregnant, in labour or who delivered or aborted up to 42 days ago arriving at health facility with any of the listed conditions or those who developed any of those conditions (organ dysfunction criteria) during their stay at the health facility were eligible.

- Cardiovascular dysfunction: Shock, cardiac arrest (absence of pulse/ heart beat and loss of consciousness), use of continuous vasoactive drugs, cardiopulmonary resuscitation, severe hypo perfusion (lactate $>5 \mathrm{mmol} / \mathrm{l}$ or $>45 \mathrm{mg} / \mathrm{dl}$ ), severe acidosis $(\mathrm{pH}<7.1)$.

- Respiratory dysfunction: Acute cyanosis, gasping, severe tachypnea (respiratory rate $>40$ breaths per minute), severe bradypnea (respiratory rate $<6$ breaths per minute), intubation and ventilation not related to anesthesia, severe hypoxemia $(\mathrm{O} 2$ saturation $<90 \%$ for $\geq 60$ minutes or $\mathrm{PAO} 2 / \mathrm{FiO} 2$ $<200)$.

- Renal dysfunction: Oliguria non-responsive to fluids or diuretics, dialysis for acute renal failure, severe acute azotemia (creatinine $\geq 300 \mu \mathrm{mol} / \mathrm{ml}$ or $\geq 3.5$ $\mathrm{mg} / \mathrm{dl})$.

- Coagulation/haematological dysfunction: Failure to form clots, massive transfusion of blood or red cells ( $\geq 5$ units), severe acute thrombocytopenia $(<50000$ platelets $/ \mathrm{ml}$ ).

- Hepatic dysfunction: Jaundice in the presence of preeclampsia, severe acute hyperbilirubinemia (bilirubin $>100 \mu \mathrm{mol} / 1$ or $>6.0 \mathrm{mg} / \mathrm{dl}$ ).

- Neurological dysfunction: Prolonged unconsciousness (lasting $\geq 12$ hours)/coma (including metabolic coma), stroke, uncontrollable fits/status epilepticus, total paralysis.

- Uterine dysfunction: Uterine hemorrhage or infection leading to hysterectomy.

Data collection of eligible women was done in the form designed by WHO, which was filled either at the time of admission or when they developed organ dysfunction.

The data were also collected for critical interventions. Using the collected data various maternal near-miss indicators, i.e., maternal near-miss ratio (MNMR), severe maternal outcome ratio (SMOR), maternal near-miss mortality ratio (MNM: 1MD), mortality index (MI) were calculated.
The study was approved by the institutional ethical committee.

Following indices were calculated:

Maternal near-miss ratio is the number of near-miss cases per 1,000 live births. MNMR is the ratio between maternal near-miss cases and maternal deaths. For this indicator, higher ratios indicate better care, meaning more women survived as a near miss rather than becoming maternal deaths.

Mortality index (MI) the number of maternal deaths was divided by the number of women with life-threatening conditions (maternal near-miss and maternal deaths) and was expressed as a percentage.

Higher indices indicate that more women with lifethreatening conditions die (low quality of care), whereas lower indices signify better quality of care.

SMOR is the number of women with life threatening conditions per 1,000 live births. This indicator gives an estimation of the amount of care and resources that would be needed in an area or facility.

\section{RESULTS}

During the period of this study (from May 2016 to April 2017) there were 2243 total antenatal admissions and 59 near miss cases. Prevalence of SAMM in the present study is $3.52 \%$.

It was observed that most of the cases, i.e. $45.76 \%$ belonged to the age group 26-30 years. The mean age was 28.46 years. Out of the entire study population majority $(71.18 \%)$ were multipara and grand multipara $(8.47 \%)$. It was seen that around $76.3 \%$ of the patients were referred from other health facilities.

Table 1: Underlying cause of SAMM (near miss and death).

\begin{tabular}{|l|l|l|}
\hline $\begin{array}{l}\text { Underlying cause of near } \\
\text { miss or death }\end{array}$ & $\begin{array}{l}\text { Near miss } \\
(\mathbf{n}=59)\end{array}$ & $\begin{array}{l}\text { Maternal } \\
\text { death }(\mathbf{n}=6)\end{array}$ \\
\hline $\begin{array}{l}\text { Pregnancy with abortive } \\
\text { out come }\end{array}$ & $12(20.3)$ & 0 \\
\hline $\begin{array}{l}\text { Obstetric haemorrhage } \\
\text { Hypertensive disorder of } \\
\text { pregnancy }\end{array}$ & $26(44.1)$ & $3(50)$ \\
\hline $\begin{array}{l}\text { Other obstetric disease or } \\
\text { complication }\end{array}$ & $4(6.8)$ & 0 \\
\hline $\begin{array}{l}\text { Medical diseases } \\
\text { associated with pregnancy }\end{array}$ & $7(11.9)$ & $3(50)$ \\
\hline $\begin{array}{l}\text { Unanticipated } \\
\text { complications of } \\
\text { management }\end{array}$ & $3(5.1)$ & 0 \\
\hline \begin{tabular}{l} 
Total \\
\hline
\end{tabular} & $59(100)$ & $6(100)$ \\
\hline
\end{tabular}


Out of the total 1675 deliveries there were 168 patients with life threatening conditions out of which 59 patients fulfilled the criteria for SAMM (severe acute maternal morbidity) which included 6 maternal deaths.

Table 1 clearly shows that Obstetric haemorrhage (which included post-partum haemorrhage, antepartum haemorrhage, rupture uterus and early pregnancy haemorrhage) was the cause for maximum number near miss cases $(44.1 \%)$ and also for $50 \%$ of maternal deaths. The maximum frequency of SAMM (near miss + maternal death) was due to severe post-partum haemorrhage $(27.1 \%$ ), followed by $18.6 \%$ cases with haemorrhage in first trimester (ectopic and abortion) as shown in Figure 1.

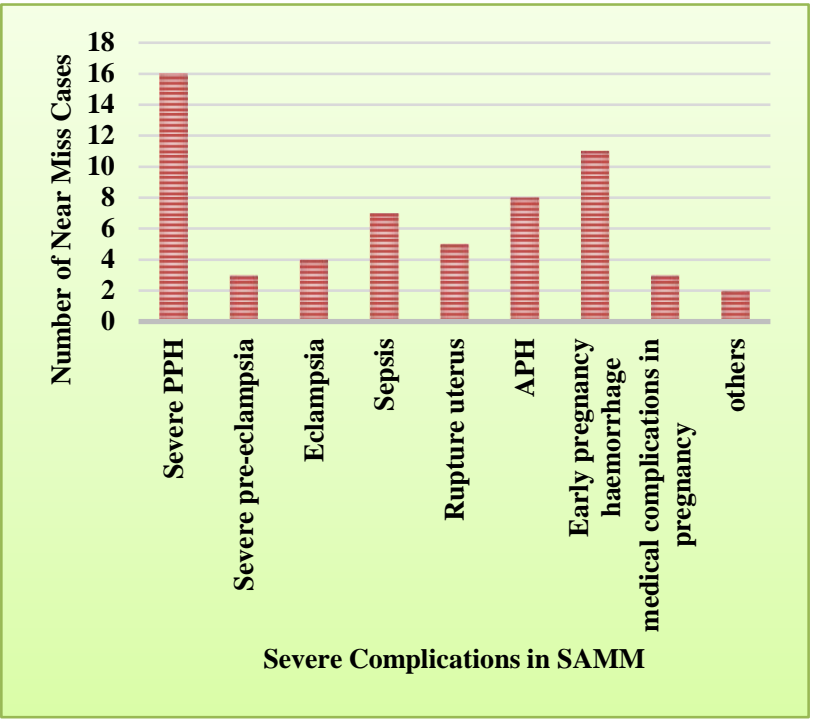

Figure 1: Severe complications in SAMM

Further as shown in Figure 2 maximum number of patients had atonic PPH. It was observed that 18 out of 59 $(30.5 \%)$ patients had multiple organ involvement. Coagulation/ hematologic dysfunction attributed to maximum number of cases (32/59). Due to massive blood loss blood transfusion was required in 42 patients out of $59(71.2 \%)$ (Figure 3).

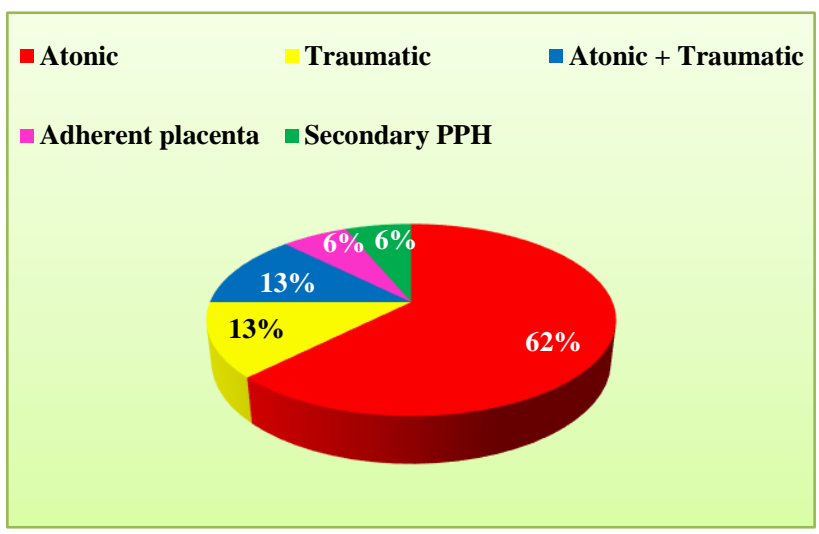

Figure 2: Causes of PPH.

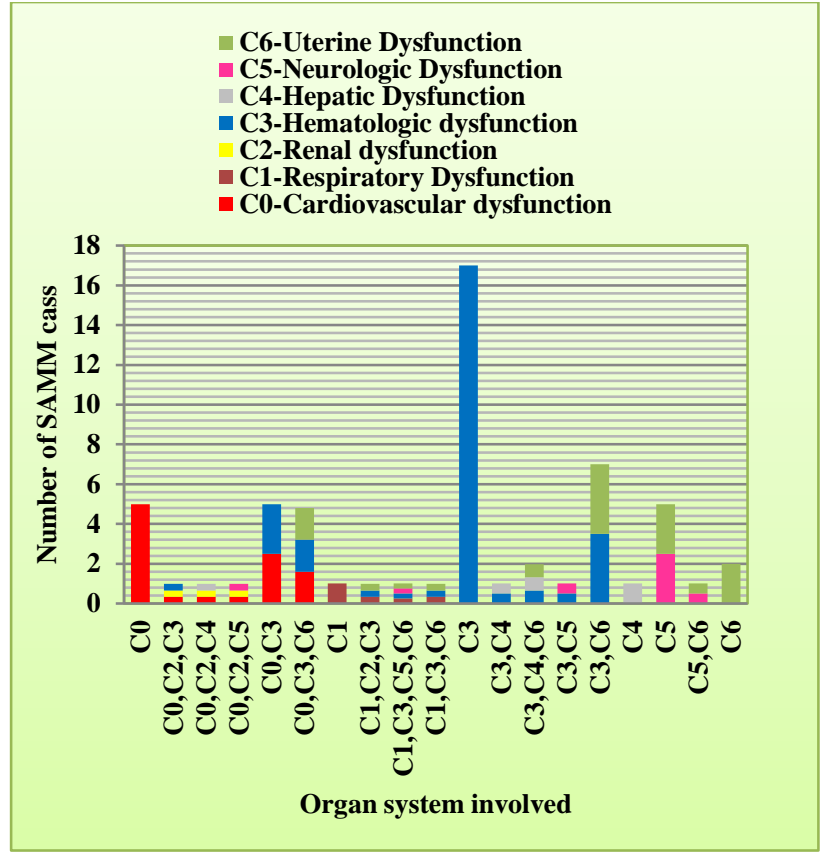

Figure 3: Organ system involvement in SAMM.

Among these $32(54.2 \%)$ patients required massive transfusions (more than 5 units of blood and blood products). It was seen that there was more than one critical intervention required in most of the cases. Laparotomy was done in 28 cases and 19 women required Emergency hysterectomy. The indication for hysterectomy in most cases (10 out of 19) was refractory PPH. Other causes included uterine rupture, uterine perforation, scar pregnancy and cervical pregnancy. Most of the cases with life threatening complications had to stay in hospital for less than 7 days. The mean duration of stay in hospital was 8 days.

Table 2: Distribution of pregnant women by maternal outcomes and near miss indicators.

\begin{tabular}{|l|l|}
\hline $\begin{array}{l}\text { Total Antenatal admissions from } \\
\text { May 2016 to A pril 2017 }\end{array}$ & 2243 \\
\hline Total number of deliveries & 1675 \\
\hline Total number of Live births & 1591 \\
\hline Total number of Intra uterine deaths & 84 \\
\hline Total number of near miss cases & 59 \\
\hline Total number of ICU admissions & 43 \\
\hline Maternal deaths & 6 \\
\hline Maternal near miss incidence ratio & $37.08 / 1000$ \\
& live births \\
\hline Maternal near miss- Mortality ratio & 9.83 \\
\hline Mortality Index & $10.17 \%$ \\
\hline Maternal mortality ratio & $\begin{array}{l}377.12 / 100,000 \\
\text { live births }\end{array}$ \\
\hline
\end{tabular}

It was observed that $45.8 \%$ women with SAMM gave birth to a live baby and maximum births i.e. $44.15 \%$ were at term (>36 week 6 days), $13.6 \%$ babies required admission to NICU, out of which 2 expired within a week 
after birth. There were 6 maternal deaths out of 59 cases of severe maternal morbidity suggesting 1 maternal death for every 9-10 women surviving life threatening complication. Severe PPH was the cause for $50 \%$ of maternal deaths (Table 2).

\section{DISCUSSION}

Obstetric morbidity and mortality remain a major challenge in developing countries despite substantial efforts. Pregnant women's health status is not reflected by mortality indicators alone. ${ }^{5}$ These indicators and maternal mortality represents the tip of an iceberg; for each death, many other women survive life threatening complications during pregnancy, child birth, and the puerperium that lead to adverse degrees of squeal. ${ }^{6}$ Hence the concept of severe acute maternal morbidity (SAMM) is apt for the present health providing system. ${ }^{7}$ Hence, new "near miss" criteria took over maternal mortality ratio. WHO criteria, 2009 are unique in considering not only clinical but also laboratory and management-based criteria. ${ }^{8}$ The present study was therefore undertaken to determine the prevalence of SAMM cases and to evaluate obstetrical complications and their antecedent causes which are replicated in maternal death. In this study authors adopted organ dysfunction criteria for enrolment of near miss cases. The mean age of SAMM cases was 28.46 years which was comparable to the mean age reported by Rathod Archana D et al and that stated in a Brazilian study.,10 Searching through published literature, MMR bulletin 2010-12 maximum number of maternal morbidities and maternal mortalities were noted in 20-24-year age group followed closely by 25-29-year age group. ${ }^{11}$ It was observed in the present study that major population of SAMM was multiparous (71.2\%). Multiparity translates into various obstetric complications especially atonic PPH and its squeal which was apparent in the present study. Souza JP et al. found similar results with around $66 \%$ of population of SAMM being multiparous. ${ }^{10}$ Whereas predominant (67.55\%) population of primiparas was reported by Rathod Archana D et al. ${ }^{9}$ It was seen that around $76.3 \%$ of the SAMM cases were referred from other health facilities thus pointing to second delay related to accessing health care due to referral chain between facilities, and sometimes into barriers in the community, which might be physical, cultural, or financial. Remaining $23.7 \%$ patients came directly to the present institute but in a moribund state reflecting first delay, which is failure of recognition by women and their families to seek care. This could be attributed to ignorance of the community and economic constraints. ${ }^{12}$

Prevalence of SAMM in the present study is $3.25 \%$. Prevalence of SAMM in other Indian studies as reported by PS Roopa et al and Pandey Amita et al was $1.77 \%$ and 9.96\% respectively. In another retrospective study Rathod Archana D et al. found prevalence of near miss being $0.73 \% .^{9,13,14}$ Souza JP et al reported prevalence of near miss to be $0.94 \% .{ }^{15}$ Prevalence of near miss stated by
Gupta Sangeeta et al $(0.51 \%)$ was significantly less when compared to the present study and was comparable to the Brazilian study. ${ }^{16}$ Tuncalp $\mathrm{O}$ et al, in their systematic review of maternal near miss across 46 countries found prevalence rates of near miss varied between 0.6 and $14.98 \%$ which was highest in African countries and lowest in European countries. ${ }^{17}$ In the present study leading cause of SAMM was Obstetric hemorrhage and was responsible for $64 \%$ of near miss and $50 \%$ of maternal deaths. PPH accounted for major proportions of Obstetric hemorrhage. Rathod AD et al. also stated in her study hemorrhage as the leading cause on near miss $(26.7 \%) .{ }^{9}$ In a Nigerian study it was observed that severe hemorrhage accounted for $41.3 \%$ of near miss followed by hypertensive disorders in pregnancy ( $37.3 \%$ cases). ${ }^{18}$ This is in contrast to a study conducted by Souza JP et al. where hypertensive disorders of pregnancy stood out as the major cause of near miss. ${ }^{10}$ Due to severe obstetric haemorrhage Blood transfusion was needed in $71.2 \%$ cases and emergency hysterectomy was contemplated in $32 \%$ women. Sangeeta Gupta et al. found results similar to present study where $73 \%$ patients required blood transfusions and $37 \%$ required emergency hysterectomy. ${ }^{16}$ Whereas a lower rate of peripartum hysterectomy was reported by Rathod $(3.72 \%)$ and Souza $\mathrm{JP}$ et al (3.2\%). Tuncalp $\mathrm{O}$ et al. in their systematic review of maternal near miss across 46 countries stated that $0.04-0.26 \%$ of near miss were submitted to emergency hysterectomy. ${ }^{17-19}$ Authors had higher incidence of peri-partum hysterectomy in the present study which is related to the fact that this institute is located in the outskirts of the city of Dehradun which amounts to delay in transportation of patients. Economic constraints also deter the patients to seek an early health care. The patients are being referred in haemorrhagic shock with variable presentation. Uterine salvage procedures- stepwise pelvic devascularisation, intrauterine packing was contemplated in these patients but due to the severity of presentation hysterectomy was eventually carried out. $44.1 \%$ of SAMM cases required admission to Intensive care unit and $47.5 \%$ patients required laparotomy for ruptured ectopic pregnancy, rupture uterus and cases of scar and cervical pregnancy. Of all the women admitted in ICU $77 \%$ were revived with aggressive management and multidisciplinary approach. A relatively low rate of ICU admission (26.7\%) was reported by Rathod Archana D et al. and a much higher rate of ICU admission $(62.6 \%)$ was reported by PS Roopa. O Tuncalp et al. in their systematic review reported that $0.04-4.54 \%$ of near miss were admitted in ICU. ${ }^{9,13,18}$ The Maternal mortality Ratio of this study is $377.12 / 100,000$ live births. Mortality Index is $10.17 \%$ and maternal near miss to mortality ratio is $9.83: 1$. In a study conducted at Kasturba Hospital MMR of $313 / 100,000$ live births and MI of $14.9 \%$ and maternal near miss to mortality ratio was 5.6: 1 was reported. ${ }^{13}$ In a Brazilian study by Souza JP et al. it was seen that MMR in the screened population was 170 maternal deaths per 100,000 live births, maternal near miss to mortality ratio was 5.5 and MI was 15.38. Apparently, MMR in present 
study may seem high compared to our western counterparts but it is comparable to the figures reported from developing countries. As the lower Mortality index reflects better quality of care, this is seen in present study as well with 9-10 women with severe maternal complications surviving for 1 maternal death. Delayed recognition of the events by the patients, delayed referral, inadequate primary care, inappropriate transfer, inadequate utilization of resources were identifiable factors which contributed to the burden of SAMM in the present study.

\section{CONCLUSION}

Prompt identification of complications and timed intervention remains the key determinant in making mothers survive a life-threatening complication. Although facilities like promotion of institutional deliveries, 108 ambulance services, cash incentives are provided by the government but the end users especially the population residing in hilly terrains are yet to derive maximum benefit out of these. Analysis of SAMM cases at this center is an eye opener that lot remains unachieved and public and private sector need to join hands in this sector.

\section{Funding: No funding sources}

Conflict of interest: None declared

Ethical approval: The study was approved by the Institutional Ethics Committee

\section{REFERENCES}

1. Social Statistics Division Ministry of Statistics and Programme Implementation Government of India. Millennium Development Goals India Country Report 2015. New Delhi; 2015;16-19.

2. WHO, UNICEF, UNFPA, The World Bank, United Nations Population Division. Trends in maternal mortality: 1990 to 2013. Geneva: World Health Organization; 2014.

3. Kalra P, Kachhwaha CP. Obstetric near miss morbidity and maternal mortality in a Tertiary Care Centre in Western Rajasthan. Indian J Public Health. 2014;58(3):199.

4. Park K. Millennium development Goals to Sustainable development goals. Title: Parks textbook of preventive and social medicine.24th ed. Bombay: Banarasidas Bhanot; 2017.p 507.

5. World Health Organization. Evaluating the quality of care for severe pregnancy complications -The WHO near- miss approach for maternal health. Geneva: World Health Organization; 2011.

6. Paruk F, Moodley J. Severe obstetric morbidity. Curr Opin Obstet Gynecol. 2001;13(6):563-8.

7. Stones W, Lim W, Al-Azzawi F, Kelly M. An investigation of maternal morbidity with identification of life-threatening 'near miss' episodes. Health Trends. 1991;23(1):13-5.

8. WHO. Evaluating the quality of care for severe pregnancy complications: the WHO near miss approach for maternal health. World Health Organization 2011.

9. Rathod AD, Chavan RP, Bhagat V, Pajai S, Padmawar A, Thool P. Analysis of near-miss and maternal mortality at tertiary referral centre of rural India. J Obstet Gynecol India. 2016;66(S1):S295-300.

10. Souza JP, Cecatti JG, Parpinelli MA, Serruya SJ, Amaral E. Appropriate criteria for identification of near-miss maternal morbidity in tertiary care facilities: a cross sectional study. BMC Pregnancy Childbirth. 2007;7(1):20.

11. Sample registration system Office of Registrar General. MMR bulletin 2010-12.; 2013. Available at http://www.censusindia.gov.in/vital_statistics/SRS_Bull etins/MMR_Bulletin-2010-12.pdf.

12. Souza JP. WHO Department of Reproductive Health and Research. Maternal Near Miss; Geneva 2011.

13. Ps R, Verma S, Rai L, Kumar P, Pai MV, Shetty J. "Near miss" obstetric events and maternal deaths in a tertiary care hospital: an audit. Journal of pregnancy. 2013;2013.

14. Pandey A, Das V, Agarwal A, Agrawal S, Misra D, Jaiswal N. Evaluation of Obstetric Near Miss and Maternal Deathsin a Tertiary Care Hospital in North India: Shifting Focus from Mortality to Morbidity. J Obstet Gynecol India. 2014; 64(6):394-9.

15. Souza JP, Cecatti JG, Haddad SM, Parpinelli MA, Costa ML, Katz L, Say L. The WHO maternal nearmiss approach and the maternal severity index model (MSI): tools for assessing the management of severe maternal morbidity. PloS one. 2012;7(8):e44129.

16. Gupta Sangeeta, Wadhwa Leena, Gupta Taru, Kumari Sushma. Evaluation of Severe Maternal Outcomes to Assess Quality of Maternal Health Care at a Tertiary Center. J Obstet Gynecol India. 2015; 65(1):23-7.

17. Adeoye IA, Onayade AA, Fatusi AO. Incidence, determinants and perinatal outcomes of near miss maternal morbidity in Ile-Ife Nigeria: a prospective case control study. BMC Pregnancy Childbirth. 2013;13(1):93.

18. Tunçalp Ö, Hindin MJ, Souza JP, Chou D, Say L. The prevalence of maternal near miss: a systematic review. BJOG: Int J Obstet Gynaecol. 2012;119(6):653-61.

19. World Health Organization. Evaluating the quality of care for severe pregnancy complications: the WHO near-miss approach for maternal health. Available at: http://apps.who.int/iris/bitstream/10665/ 44692/1/9789241502221_eng.pdf.

Cite this article as: Verma L, Nautiyal R, Aggarwal P. Evaluation of severe acute maternal morbidity and mortality at a tertiary referral center of Uttarakhand, India. Int J Reprod Contracept Obstet Gynecol 2019;8:1601-5. 